\title{
Repetition priming in an auditory lexical decision task: Effects of lexical status
}

\author{
MASARU MIMURA \\ Tokyo Dental College Ichikawa General Hospital, Ichikawa, Japan \\ and Boston University School of Medicine, Boston, Massachusetts \\ MIEKE VERFAELLIE \\ Boston University School of Medicine, Boston, Massachusetts \\ and Boston Veterans Affairs Medical Center, Boston, Massachusetts \\ and \\ WILLIAM P. MILBERG \\ Boston University School of Medicine, Boston, Massachusetts \\ and GRECC, West Roxbury Veterans Affairs Medical Center, West Roxbury, Massachusetts
}

\begin{abstract}
The effect of lexical status on the time course of repetition priming was examined in an auditory lexical decision task. Words and nonwords were repeated at lags of $0,1,4$, and 8 items (Experiment 1A) and 0, 2, 4, and 8 items (Experiment 1B). The pattern of repetition effects differed for words and nonwords in that repetition priming for nonwords at lag 0 was significantly greater than for words. The magnitude of this effect decreased when one or more items intervened. A second experiment, replicating Experiment $1 \mathrm{~A}$ with visual presentation, clarified that the greater magnitude of repetition priming for nonwords at lag 0 is unique to the auditory modality. This finding suggests that in the course of forming a stable perceptual representation, the details of the acoustic/phonological information of an auditory stimulus are more readily available for nonwords than for words. The capacity to carry this phonological information is limited, however, and can only be maintained until another stimulus is encountered.
\end{abstract}

Most of the available data concerning the phenomenon of repetition priming come from experiments employing visually presented materials. Consequently, the characteristics and mechanisms of visual priming are better understood than those of auditory priming (Schacter, Chiu, \& Ochsner, 1993; Schacter \& Church, 1992). Nonetheless, some of the phenomena known to occur with visually presented words find their analogue in the auditory domain. For example, when subjects are asked to identify stimuli masked in noise, previously studied items can be identified more readily than nonstudied items (Ellis, 1982; Franks, Plybon, \& Auble, 1982; Jackson \& Morton, 1984; Kempley \& Morton, 1982; Schacter, Church, \& Treadwell, 1994). In auditory stem completion tasks, the likelihood of responding with previously studied words is greater than that of responding with nonstudied words (Bassili, Smith, \& MacLeod, 1989; McClelland \& Pring, 1991). In both paradigms, priming is sensitive to changes in modality of stimulus presentation (Clarke \& Morton, 1983; Jackson \& Morton, 1984; Jacoby, 1983;

This research was supported by NINDS Grant NS 26985 to Boston University School of Medicine and by a VA Merit Review Grant to W.P.M. Correspondence should be addressed to M. Mimura, Department of Neuropsychiatry, Tokyo Dental College Ichikawa General Hospital, 5-11-13 Sugano, Ichikawa, 272 Japan (e-mail: mimuram (amb.tokyo.infoweb.or.jp).
Kirsner \& Smith, 1974). Again by analogy with the visual domain, these findings have been taken as evidence for the existence of an auditory perceptual representation system that mediates the observed repetition effects.

An area where differences may arise between priming for auditory and visual stimuli concerns the effect of lexical status on priming magnitude. This difference has been noted in the context of the lexical decision paradigm, in which subjects must simply decide whether a stimulus is a word or not. It is well established in the visual domain that words with a preexisting representation produce larger and more reliable priming effects than do nonwords that are not associated with a known lexical or semantic representation (Bentin \& Moscovitch, 1988; Kersteen-Tucker, 1991; Rueckl, 1990; Scarborough, Cortese, \& Scarborough, 1977). A similar finding was obtained in the auditory domain by Kirsner and Smith (1974). More recently, however, Milberg and colleagues (Milberg, Blumstein, \& Dworetzky, 1988; Milberg, Blumstein, Saffran, Hourihan, \& Kurowski, 1993) found that the effect of lexicality on the magnitude of priming interacted with the number of items intervening between the first and second presentations of target stimuli. At a lag of 0 , priming for nonwords exceeded that of words. However, by a lag of 4 , the next interval tested, priming was already smaller for nonwords than for words. This finding raises the possibility that lexical status has dif- 
ferent effects on repetition priming which depend on the sensory modality, a notion that is consistent with other findings suggesting a difference between visual and auditory memory (Crowder, 1972).

Because auditory stimuli have been used to examine priming in the lexical decision paradigm in only a few studies, the present study was designed in order to examine more closely the course of priming for auditorily presented words and nonwords at short lags. Of particular interest were changes in the priming pattern that might occur over the intervals sampled because these changes might reflect characteristics of the auditory processing system. To track these changes, auditory priming was studied at lags of $0,1,2,4$, and 8 intervening items (Experiment 1). This was accomplished in two repetition priming tasks employing the lexical decision paradigm: In the first, the effect of lexicality on priming was examined at lags of $0,1,4$, and 8 (Experiment $1 \mathrm{~A})$; in the second, the lags were $0,2,4$, and 8 (Experiment 1B). The short lags were distributed across the two tasks within Experiment 1 so that subjects would be less likely to use explicit memory to predict upcoming targets in a manner that would undermine the implicit nature of the task. In order to examine differences between auditory and visual repetition priming, in Experiment 2 priming was examined in a lexical decision task with visual stimuli.

\section{EXPERIMENTS 1A-1B}

\section{Method}

Subjects. Twenty-four Boston University undergraduates participated as paid volunteers in this pair of experiments. Twelve were assigned to Experiment $1 \mathrm{~A}$, and 12 were assigned to Experiment $1 \mathrm{~B}$.

Materials and Design. The target stimuli included 240 one- or two-syllable nouns selected from Francis and Kučera (1982), with frequencies ranging from 1 to 100 occurrences per million words. One hundred twenty of these words were used as real word stimuli, and the other 120 were used to construct nonwords. This was done by systematically replacing a single letter in each word, with the provision that the resulting nonword must conform to the phonological properties of English. Both the real words and the nonwords were randomly divided into 80 targets and 40 fillers. Within each stimulus list, targets were repeated at lags of $0,1,4$, or 8 intervening items (Experiment $1 \mathrm{~A}$ ) or at lags of $0,2,4$, or 8 intervening items (Experiment $1 B$ ). Thus, at lag 0 , the second presentation immediately followed the first. At lag 8 , there were 8 items intervening between the two presentations of the target. Fillers occurred only once in a list.

The experiment consisted of 240 trials divided into two sessions. In each session, 5 word and 5 nonword targets were repeated at each of the four lags. Twenty words and 20 nonwords were used as fillers to complete each session.

The stimuli, pronounced by a male speaker, were digitized on a MacRecorder analog-to-digital input device at 8 bits, $22 \mathrm{MHz}$, and they were stored on the computer hard drive for use in the experiment.

Procedure. The subject was seated in front of a 13-in. computer monitor in a semi-darkened room. On each trial, the computer presented a single auditory word/nonword stimulus to the subject through headphones. The subject was asked to respond as quickly as possible by pressing the "yes" key if he/she was hearing a real English word or by pressing the "no" key if he/she was hearing a nonword. The next trial was initiated $2,000 \mathrm{msec}$ following the subject's response.

\section{Results}

To compute reaction times (RTs), only responses to targets that were correct on both presentations were included. In Experiment 1A, the mean proportion of errors was . $9 \%$ for words and $4.1 \%$ for nonwords. In Experiment $1 \mathrm{~B}$, the corresponding error rates were $.8 \%$ and $7.3 \%$. Although the error rate was higher for nonwords than for words, errors were not systematically related to lag and therefore will not be discussed further.

Experiment 1A. As can be seen in Figure 1, RTs to the second presentation were faster than those to the first presentation, and RTs were faster for words than for nonwords. In addition, the effect of repeated presentation as a function of lag was different for words and nonwords. Most strikingly, the benefit associated with immediate
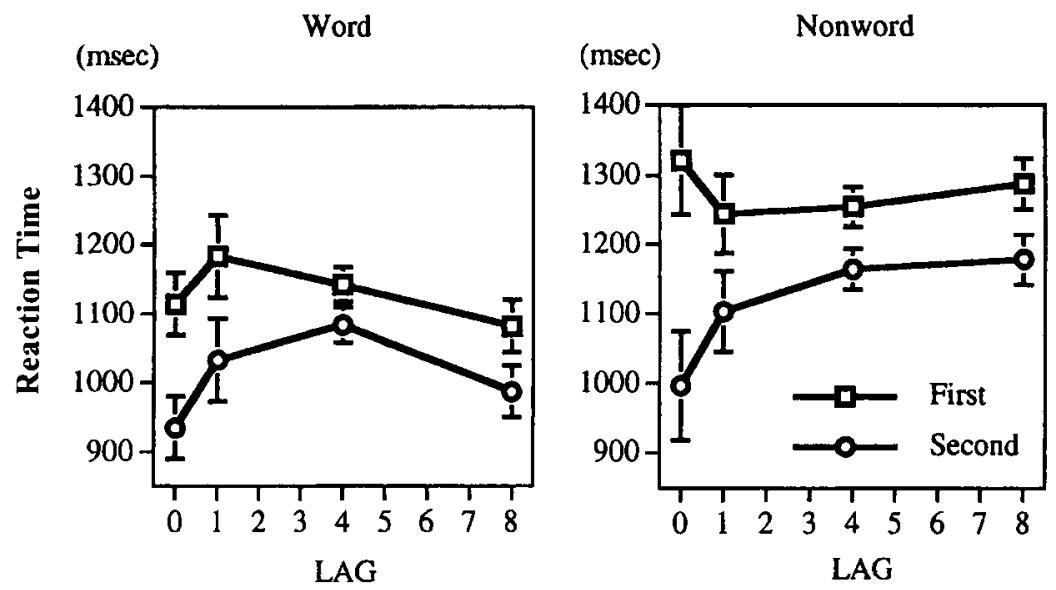

Figure 1. Mean reaction time to words and nonwords as a function of lag and presentation in Experiment 1A. Confidence intervals are based on the $11 \mathrm{df}$ error term from the one-way, two-level (first vs. second presentation) ANOVA performed at that lag. 
Table 1

ANOVA Table for Reaction Time of the Auditory Lexical Decision Task (Experiment 1)

\begin{tabular}{|c|c|c|c|c|c|c|c|}
\hline \multirow[b]{2}{*}{ Source } & \multirow[b]{2}{*}{$d f$} & \multicolumn{3}{|c|}{ Experiment $1 \mathrm{~A}$} & \multicolumn{3}{|c|}{ Experiment 1B } \\
\hline & & $M S$ & $F$ & $p$ & $M S$ & $F$ & $p$ \\
\hline Stimulus type & 1 & $735,433.92$ & 33.78 & .0001 & $1,268,702.79$ & 20.52 & .0009 \\
\hline Presentation & 1 & $988,815.49$ & 46.46 & .0001 & $575,751.02$ & 233.76 & .0001 \\
\hline Lag & 3 & $40,541.23$ & 7.50 & .0006 & $78,146.89$ & 9.33 & .0001 \\
\hline Stim. $\times$ present. & 1 & $25,091.59$ & 5.65 & .0367 & $2,164,11$ & 0.64 & .44 \\
\hline Stim. $\times$ lag & 3 & $39,437.53$ & 5.46 & .004 & $38,326.54$ & 8.57 & .0002 \\
\hline Present. $\times$ lag & 3 & $72,360.08$ & 13.46 & .0001 & $73,695.93$ & 13.35 & .0001 \\
\hline Stim. $\times$ present. $\times$ lag & 3 & $14,029.53$ & 7.00 & .0009 & $19,179.269$ & 2.86 & .05 \\
\hline
\end{tabular}

repetition (i.e., lag 0 ) was greater for nonwords than for words. These effects were confirmed in a repeated measures analysis of variance (ANOVA) with the independent variables of stimulus type (word or nonword), presentation (first or second), and lag $(0,1,4$, or 8$)$. The results of this analysis are presented in Table 1 .

For words, repetition effects (RT2 - RT1) were significant throughout the lags (lag $0, M=179 \mathrm{msec}, S E=$ $29 \mathrm{msec} ;$ lag $1, M=150 \mathrm{msec}, S E=39 \mathrm{msec} ; \operatorname{lag} 4, M=$ $58 \mathrm{sec}, S E=16 \mathrm{msec} ; \operatorname{lag} 8, M=95 \mathrm{msec}, S E=24 \mathrm{msec}$ ). The repetition effect was larger at lag 1 than at lag 4 $[F(1,11)=8.69, p<.01]$. However, there was no difference in the magnitude of the repetition effect between lags 0 and $1[F(1,11)=0.84, p>.10]$ or between lags 4 and 8 $[F(1,11)=1.39, p>.10]$. For nonwords, repetition effects were also significant throughout the lags (lag 0 , $M=324 \mathrm{msec}, S E=51 \mathrm{msec} ;$ lag $1, M=140 \mathrm{msec}, S E=$ $37 \mathrm{msec}$; lag $4, M=91 \mathrm{msec}, S E=19 \mathrm{msec} ; \operatorname{lag} 8, M=$ $110 \mathrm{msec}, S E=23 \mathrm{msec}$ ). The magnitude of the repetition effect was significantly larger at lag 0 than at lag 1 $[F(1,11)=22.78, p<.0001]$, but it did not differ between lags 1 and $4[F(1,11)=1.64, p>.10]$ or lags 4 and 8 $[F(1,11)=0.25, p>.10]$.

To take into account baseline differences in RTs to words and nonwords, we also computed proportional priming scores, defined as (RT1 - RT2)/RT1. These scores, computed separately for words and nonwords at each lag, are shown in Figure 2. Proportional priming scores differed significantly between words and nonwords at lag 0 , but not at lag 1,4 , or 8 . These results were analogous to those obtained with the raw RTs described above.

Experiment 1B. Mean RTs as a function of lag and presentation for words and nonwords are shown in Figure 3. The results were remarkably similar to those in Experiment $1 \mathrm{~A}$. Most importantly, the effect of immediate repetition (i.e., lag 0 ) was again greater for nonwords than for words. The results of the ANOVA confirming these observations are also presented in Table 1.

For words, repetition effects were significant throughout the lags $(\operatorname{lag} 0, M=159 \mathrm{msec}, S E=19 \mathrm{msec} ; \operatorname{lag} 2, M=$ $107 \mathrm{msec}, S E=28 \mathrm{msec} ; \operatorname{lag} 4, M=92 \mathrm{sec}, S E=26 \mathrm{msec}$; lag $8, M=54 \mathrm{msec}, S E=12 \mathrm{msec}$ ). There was no difference in the magnitude of repetition effects between lags 0 and $2[F(1,11)=2.55, p>.10]$, lags 2 and $4[F(1,11)=$ $0.20 . p>.10]$, and lags 4 and $8[F(1,11)=1.33 . p>.10]$. For nonwords, repetition effects were significant at lags 0
$(M=286 \mathrm{msec}, S E=42 \mathrm{msec})$ and $2(M=99 \mathrm{msec}, S E=$ $32 \mathrm{msec})$, but not at lags $4(M=30 \mathrm{msec}, S E=30 \mathrm{msec})$ and $8(M=51 \mathrm{msec}, S E=39 \mathrm{msec})$. The repetition effect for nonwords was significantly greater at lag 0 than at lag $2[F(1,11)=11.66, p<.01]$, whereas repetition effects were equivalent at lags 2 and $4[F(1,11)=1.38, p>$ $.10]$ and at lags 4 and $8[F(1,11)=0.15, p>.10]$.

As in Experiment 1A, a proportional priming score was computed for each subject for each lag (Figure 4). The proportional priming score differed significantly between words and nonwords at lag 0 , but not at lags 2,4 , or 8 .

Experiments $1 \mathrm{~A}$ and $1 \mathrm{~B}$ combined. To examine the course of repetition priming across the full range of lags, the results of Experiments $1 \mathrm{~A}$ and $1 \mathrm{~B}$ were subjected to a regression analysis combining all available data. This was possible because preliminary $t$ tests did not show any differences between RTs of the subjects in Experiments $1 \mathrm{~A}$ and $1 \mathrm{~B}$ at any of the lags used. Figure $5 \mathrm{de}-$ picts the proportional priming score for words and nonwords at each lag. The priming score at lag 1 was computed based on the basis of the results of Experiment 1A, whereas the score at lag 2 was based on the results of Experiment $1 \mathrm{~B}$. Priming scores at lags 0,4 , and 8 were com-

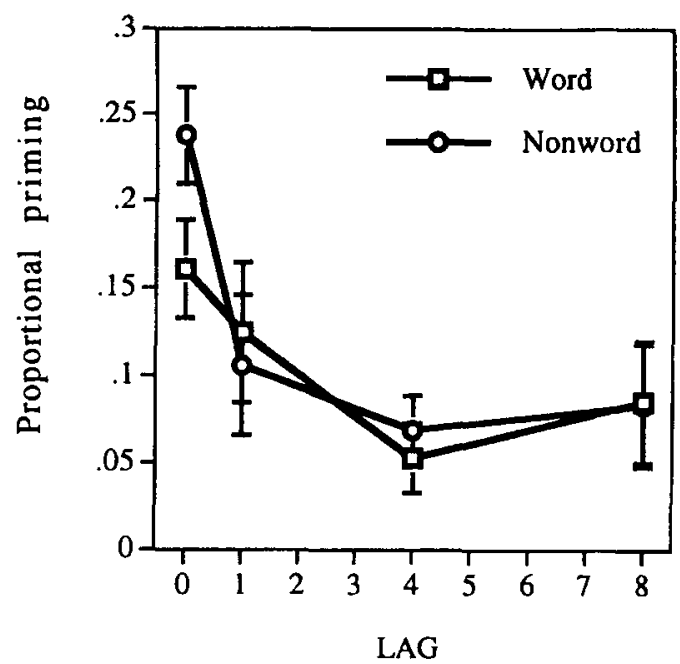

Figure 2. Proportional priming scores for words and nonwords at lags $0,1,4$, and 8 in Experiment $1 \mathrm{~A}$. Confidence intervals are based on the $11 d f$ error term from the one-way, two-level (words vs. nonwords) ANOVA performed at that lag. 

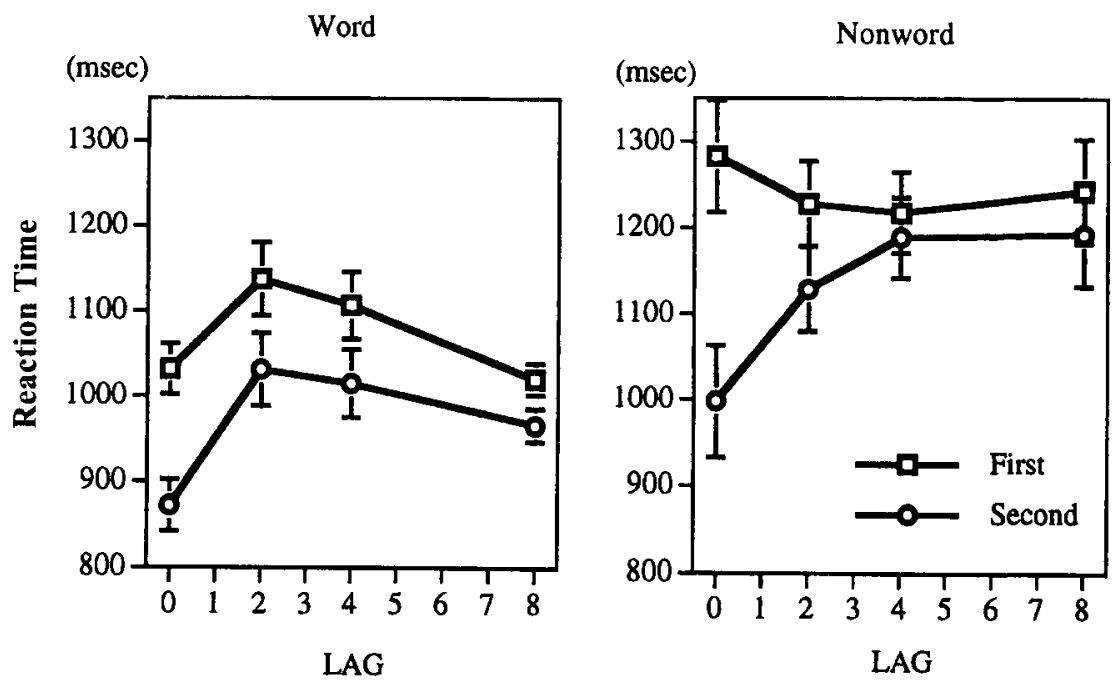

Figure 3. Mean reaction time to words and nonwords as a function of lag and presentation in Experiment 1B. Confidence intervals are based on the $11 \mathrm{df}$ error term from the one-way, two-level (first vs. second presentation) ANOVA performed at that lag.

puted by randomly choosing the data of 6 subjects from each experiment. For word trials, a linear regression analysis was significant $(R=.89, p<.05)$ and accounted for $78.6 \%$ of the variance. Although a second-order polynomial analysis was also significant $(R=.99, p=.01)$, most of the variance was still accounted for by the linear component. For nonwords, a linear regression did not reach significance $(R=.63, p>.10)$. The linear component only accounted for $40.2 \%$ of the variance. The secondorder polynomial regression was significant $(R=.95$, $p<.01$ ) and accounted for $89.7 \%$ of the variance. Examination of the polynominal regression for words and nonwords, as presented in Figure 5, suggests that the slope for the nonlinear component was greater for nonwords than for words.

\section{EXPERIMENT 2}

To examine whether the larger repetition effect for nonwords than for words at lag 0 was specific to the auditory modality, a visual analogue of Experiment $1 \mathrm{~A}$ was conducted. Because in the auditory modality the magnitude of the repetition effect at a lag of 1 was identical to that at a lag of 2 , we felt that it was sufficient to examine priming in the visual modality at the lags of $0,1,4$, and 8 .

\section{Method}

Subjects. Twelve university undergraduates who were not included in Experiment 1 participated as paid volunteers in this experiment.

Materials and Design. The materials and design were identical to those in Experiment $1 \mathrm{~A}$, except that the stimuli were presented visually on a Macintosh computer monitor. Stimuli were presented in lowercase Geneva 24-point type.

Procedure. The subject was seated $60 \mathrm{~cm}$ in front of a 13 -in. computer monitor. On each trial, the subject was presented with a single word/nonword stimulus on the screen for $500 \mathrm{msec}$. The subject was asked to respond as quickly as possible by pressing the "yes" key if he/she saw a real English word or by pressing the "no" key if he/she saw a nonword. A fixation point was not used. The next trial was initiated $2,000 \mathrm{msec}$ following a subject's response.

\section{Results}

The mean error rate was . $8 \%$ for words and $2.7 \%$ for nonwords. The error rate was higher for nonwords than for words, but the errors were not systematically related to lag and will not be discussed further.

Mean RTs to targets that were correct on both presentations are presented in Figure 6. As can be seen, RTs were faster to the second presentation than to the first presentation and were faster for words than for nonwords. In addition, the effect of repetition was similar for

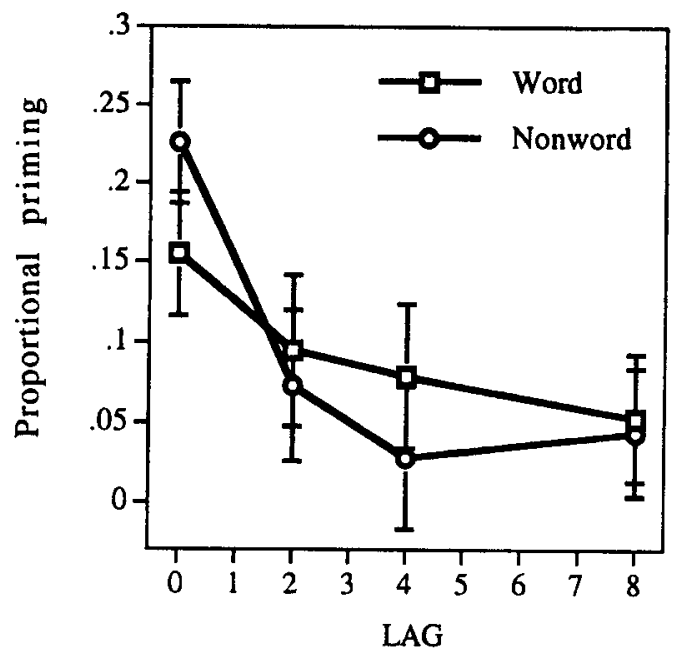

Figure 4. Proportional priming scores for words and nonwords at lags $0,2,4$, and 8 in Experiment $1 B$. Confidence intervals are based on the $11 d f$ error term from the one-way, two-level (words vs. nonwords) ANOVA performed at that lag. 


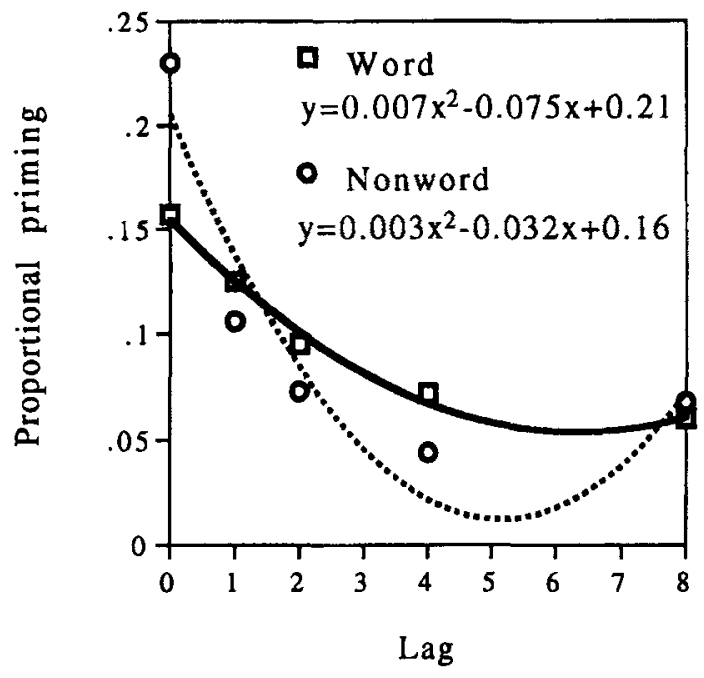

Figure 5. Auditory repetition priming as a function of lexical status and lag.

words and nonwords. These effects were confirmed in a repeated measures ANOVA, the results of which are summarized in Table 2.

For words, repetition effects were significant throughout the lags (lag $0, M=104 \mathrm{msec}, S E=13 \mathrm{msec}$; lag 1, $M=49 \mathrm{msec}, S E=10 \mathrm{msec} ;$ lag $4, M=34 \mathrm{sec}, S E=$ $16 \mathrm{msec}$; lag $8, M=46 \mathrm{msec}, S E=20 \mathrm{msec}$ ). The magnitude of the effect was greater at lag 0 than at lag 1 $[F(1,11)=10.51, p<.01]$, but was equivalent at lags 1 and $4[F(1,11)=0.82, p>.10]$ and at lags 4 and 8 $[F(1,11)=0.50, p>.10]$. For nonwords, repetition effects were also significant throughout the lags (lag $0, M=$ $86 \mathrm{msec}, S E=20 \mathrm{msec}$; lag 1, $M=43 \mathrm{msec}, S E=15 \mathrm{msec}$; lag $4, M=45 \mathrm{sec}, S E=10 \mathrm{msec} ;$ lag $8, M=30 \mathrm{msec}$, $S E=17 \mathrm{msec}$ ). The magnitude of the effect was again greater at lag 0 than at lag $1[F(1,11)=6.30, p<.05]$ and was equivalent at lags 1 and $4[F(1,11)=0.12, p>.10]$ and at lags 4 and $8[F(1,11)=0.79, p>.10]$.

As in Experiment 1, a proportional priming score was computed for each subject for each lag. There were no differences between the proportional priming scores for words and nonwords at any lag, including lag 0 (Figure 7). These findings are in contrast to the results of Experiment 1 , in which proportional priming was greater for nonwords than for words at lag 0 . This impression was confirmed in a combined analysis of Experiments 1A and 2 (Table 3 ), which revealed a significant interaction of modality, lexical status, and lag. Additional contrasts between cell means also indicated that the only difference in the magnitude of proportional priming across modalities occurred for nonwords at lag 0 [auditory vs. visual, $F(1,22)=15.30, p<.001]$.

\section{DISCUSSION}

The results of Experiment 1 demonstrate several differences in the pattern of priming for auditorily presented words and nonwords. First, repetition effects for words were robust at all five lags $(0,1,2,4,8)$, whereas for nonwords these effects were consistently obtained only at the shortest lags $(0,1$, and 2$)$. Second, and more strikingly, a significantly greater repetition effect was obtained for nonwords than for words at lag 0 . This greater effect for nonwords was immediately reduced in magnitude by lag 1 , and the repetition effects for both words and nonwords at lag 1 and thereafter were equivalent. These findings differ from those obtained in Experiment 2 , in which stimuli were presented visually. With visual presentation, repetition effects at lag 0 were equivalent for words and nonwords. A similar finding has been obtained in a number of other studies with visual presentation (Bentin \& Moscovitch, 1988; KersteenTucker, 1991; McKone, 1995). Taken together, the results of Experiments 1 and 2 indicate that the greater magni-
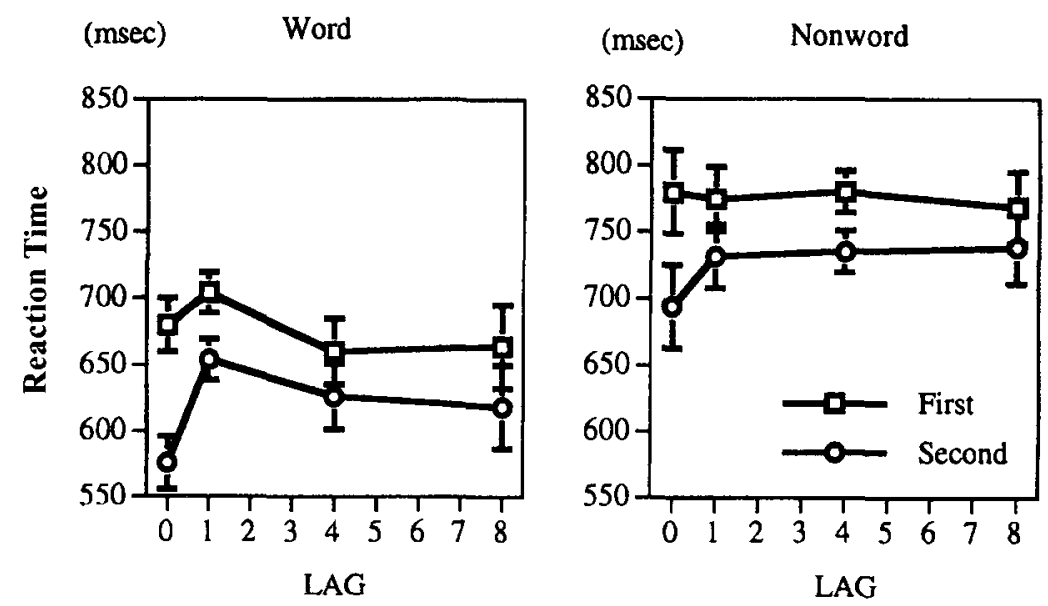

Figure 6. Mean reaction time to words and nonwords as a function of lag and presentation in the visual lexical decision task (Experiment 2 ). Confidence intervals are based on the $11 d f$ error term from the one-way, two-level (first vs. second presentation) ANOVA performed at that lag. 
Table 2

ANOVA Table for Reaction Time of the

Visual Lexical Decision Task (Experiment 2)

\begin{tabular}{lcrrc}
\hline \multicolumn{1}{c}{ Source } & $d f$ & \multicolumn{1}{c}{$M S$} & \multicolumn{1}{c}{$F$} & $p$ \\
\hline Stimulus type & 1 & $510,571.88$ & 80.23 & .0001 \\
Presentation & 1 & $143,718.80$ & 69.41 & .0001 \\
Lag & 3 & $9,327.20$ & 4.72 & .0076 \\
Stim. $\times$ present. & 1 & 663.80 & 0.33 & .5718 \\
Stim. $\times$ lag & 3 & $4,451.10$ & 2.82 & .0540 \\
Present. $\times$ lag & 3 & $8,736.21$ & 5.05 & .0055 \\
Stim. $\times$ present. $\times$ lag & 3 & 534.19 & 0.63 & .6032 \\
\hline
\end{tabular}

Table 3

ANOVA Table for Proportional Priming Scores of the Auditory Lexical Decision Task (Experiment 1A) and the Visual Lexical Decision Task (Experiment 2)

\begin{tabular}{|c|c|c|c|c|}
\hline Source & $d f$ & $M S$ & $F$ & $p$ \\
\hline Modality & 1 & .085 & 8.23 & .0089 \\
\hline Stimulus type & 1 & .01 & 0.02 & .8928 \\
\hline Lag & 3 & .113 & 19.54 & .0001 \\
\hline Modality $\times$ stim. & 1 & .018 & 3.35 & .0807 \\
\hline Modality $\times$ lag & 3 & .008 & 1.47 & .2317 \\
\hline Stim. $\times$ lag & 3 & .004 & 1.66 & .1833 \\
\hline Modality $\times$ stim $\times$ lag & 3 & .010 & 4.26 & .0083 \\
\hline
\end{tabular}

tude of repetition priming for nonwords at lag 0 is unique to the auditory modality.

Given the modality-specificity of our findings, it is unlikely that the observed word/nonword differences in the auditory modality were due to the operation of an explicit retrieval strategy. For example, it could be argued that when a stimulus is repeated at a lag of 0 , subjects remember the response that they have just made, and consequently, they do not have to make a lexical decision again. Nonwords would therefore show larger repetition effects than words, because baseline lexical decision latencies are longer for nonwords than for words. The comparison of the results in the auditory and visual modality, however, rules out such an interpretation. If it were the case that lexical differences resulted from the use of explicit strategies, we would expect greater repetition effects for nonwords than for words at lag 0 in the visual modality as well. This was not the case. Therefore, the observed word/ nonword differences across modalities suggest that the processes mediating visual and auditory memory have distinct operating characteristics, making the effect of lexical status more critical to the latter.

Regardless of lexical status, auditory stimuli are first analyzed according to a number of acoustic parameters signaling fundamental frequency, timbre, and volume, ultimately leading to the perception of phonetic distinctive features. For words, this phonetic information is segmented and assembled into lexical units which may then be interpreted for meaning. For nonwords, the same acoustic or phonological analysis does not lead to the activation of lexical or semantic representations. The finding of greater repetition priming for immediately repeated nonwords than for words suggests that the details of the phonological information of a potential lexical stimulus are more readily available for nonwords than for words. It is quite possible that the process by which real word stimuli contact stored lexical/semantic representations dampens or interferes with the availability of relatively veridical phonological information, as more permanent, abstract versions of the information are rapidly activated. In contrast, when a nonword stimulus is presented, relatively detailed phonological information is maintained for a longer time period because it requires the formation of a novel representation. The drop in nonword priming to asymptotic levels by lag 1 suggests that the capacity to carry high-resolution phonological information is limited and can be maintained only until another stimulus is encountered.

This analysis may explain the inconsistency between the present results and those of Kirsner and Smith (1974), who did not show differences in the magnitude of auditory priming for words and nonwords at lag 0 . In their study, lexical decision responses were made verbally ("yes" or "no"). The auditory information inherent in these responses may have interfered with the storage of phonological information, thus eliminating the larger nonword repetition effect at lag 0 .

Although it is not known how long this phonological information can be maintained, it is interesting that most estimates of a hypothetical auditory sensory store for pitch, loudness, and timbre are limited to approximately 250 msec (Cowan, 1987; Kallman \& Massaro, 1983). Given the temporal parameters of the present experiment, it appears that the acoustic information that allows for phonological interpretation of nonwords is maintained for a far longer period of time, perhaps on the order of a few seconds. The information in this phonological store is sensitive to interference and may be discarded or inhibited once a stimulus has received a lexical interpretation.

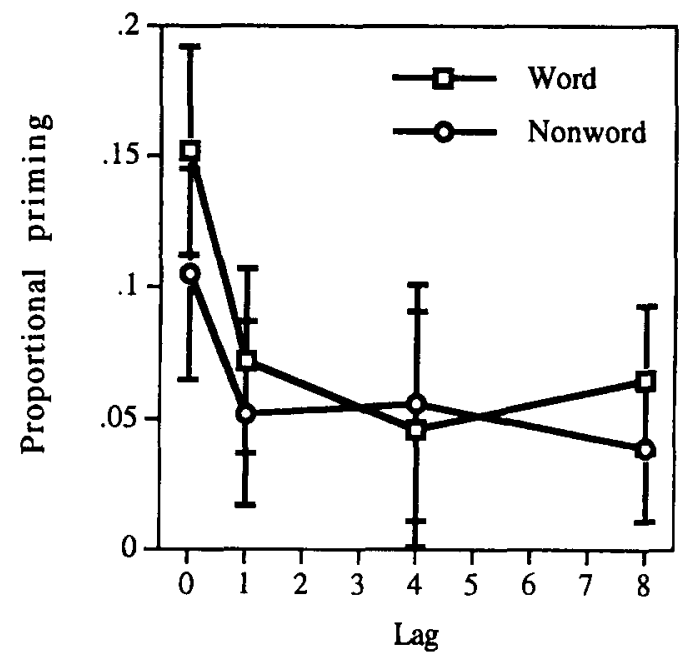

Figure 7. Proportional priming scores for words and nonwords at lags $0,1,4$, and 8 in the visual lexical decision task (Experiment 2). Confidence intervals are based on the $11 d f$ error term from the one-way, two-level (words vs. nonwords) ANOVA performed at that lag. 
Why do similar word/nonword differences not occur in the visual modality? An important difference between visual and auditory information is related to the temporal processing demands of the latier. Representations of auditorily presented speech stimuli must be segmented and formed from an evanescent signal presented over time, making this process susceptible to noise and highly dependent on the ability to maintain a record of phonological information. Since written information is generally not presented with severe temporal restrictions and segmentation is intrinsic to the modality, the demands for the maintenance of precise veridical representations may be less - hence the finding of equivalent priming for words and nonwords. Note that a similar distinction has been proposed elsewhere (Crowder \& Morton, 1969).

Additional research is needed in order to specify the exact nature of the acoustic information held in the hypothetical phonological store suggested by the present data. Our findings indicate that this store is highly susceptible to interference but do not provide information on its ability to maintain veridical phonological representations without interference. In addition, we have suggested that the observed lexical status effects are due to the fact that real words contact semantic representations. Words and nonwords, however, also differ in their familiarity. It is therefore possible that with repeated exposure, nonwords would behave more as words do, despite their lack of semantic representation. These and other issues remain to be resolved. Nevertheless, the present results indicate that the principles that govern the formation of auditory representations are distinct from those that govern the formation of visual representations.

\section{REFERENCES}

Bassili, J. N., Smith, M. C., \& MacLeod, C. M. (1989). Auditory and visual word-stem completion: Separating data-driven and conceptually driven processes. Quarterly Journal of Experimental Psychology, 41A, 439-453.

Bentin, S., \& Moscovitch, M. (1988). The time course of repetition effects for words and unfamiliar faces. Journal of Experimental Psychology: General, 117, 148-160.

Clarke, R., \& Morton, J. (1983). Cross modality facilitation in tachistoscopic word recognition. Quarterly Journal of Experimental Psychology, 35A, 79-96.

Cowan, M. (1987). Auditory sensory storage in relation to the growth of sensation and acoustic information extraction. Journal of Experimental Psychology: Human Perception \& Performance, 14, 204-215.

CRowDER, R. G. (1972). Visual and auditory memory. In J. F. Kavanagh \& I. G. Mattingly (Eds.), Language by ear and by eye: The rela- tionships between speech and reading (pp. 251-275). Cambridge, MA: MIT Press.

Crowder, R. G., \& MoRTon, J. (1969). Precategorical acoustic storage (PAS). Perception \& Psychophysics, 5, 365-373.

ELLIS, A. (1982). Modality-specific repetition of auditory word recognition. Current Psychological Research, 2, 123-128.

FRANCIS, W. N., \& KUČERA, H. (1982). Frequency analysis of English usage: Lexicon and grammar. Boston: Houghton Mifflin.

Franks, J. J., Plybon, C. J., \& Auble, P. M. (1982). Units of episodic memory in perceptual recognition. Memory \& Cognition, 10, $62-68$.

JACKSON, A., \& MORTON, J. (1984). Facilitation of auditory word recognition. Memory \& Cognition, 12, 568-574.

JACOBY, L. (1983). Perceptual enhancement: Persistent effects of an experience. Journal of Experimental Psychology: Learning, Memory, \& Cognition, 9, 21-38.

Kallman, H. J., \& Massaro, D. W. (1983). Backward masking, the suffix effect and pre-perceptual auditory storage. Journal of Experimental Psychology: Learning, Memory, \& Cognition, 9, 312-327.

Kempley, T., \& MORTON, J. (1982). The effects of priming with regularly and irregularly related words in auditory word recognition. British Journal of Psychology, 73, 441-454.

KERSTEEN-TUCKER, Z. (1991). Long-term repetition priming with symmetrical polygons and words. Memory \& Cognition, 19, 37-43.

KirSnER, K., \& SMITH, M. C. (1974). Modality effects in word identification. Memory \& Cognition, 2, 637-640.

MCClelland, A. G. R., \& Pring, L. (1991). An investigation of crossmodality effects in implicit and explicit memory. Quarterly Journal of Experimental Psychology, 43A, 19-33.

MCKONE, E. (1995). Short-term implicit memory for words and nonwords. Journal of Experimental Psychology: Learning, Memory, \& Cognition, 21, 1108-1126.

Milberg, W., Blumstein, S., \& Dworetzky, B. (1988). Phonological factors in lexical access: Evidence from an auditory lexical decision task. Bulletin of the Psychonomic Society, 26, 305-308.

Milberg, W., Blumstein, S., Saffran, J., Hourihan, J., \& Kurowski, K. (1993, October). The stability of phonological representations in aphasia: Evidence from a repetition priming task. Paper presented at the 31st Annual Meeting of the Academy of Aphasia, Tucson, Arizona.

RUECKL, J. G. (1990). Similarity effects in words and pseudoword repetition priming. Journal of Experimental Psychology: Learning, Memory, \& Cognition, 16, 374-391.

SCARborough, D., Cortese, C., \& SCarborough, H. (1977). Frequency and repetition effects in lexical memory. Journal of Experimental Psychology: Human Perception \& Performance, 3, 1-17.

SChacter, D. L., Chiv, C.-Y. P., \& OChSNeR, K. N. (1993). Implicit memory: A selective review. Annual Review of Neuroscience, 16, $159-182$

SCHACTER, D. L., \& ChURCh, B. A. (1992). Auditory priming: Implicit and explicit memory for words and voices. Journal of Experimental Psychology: Learning, Memory, \& Cognition, 18, 915-930.

Schacter, D. L., Church, B. A., \& Treadwell, J. (1994). Implicit memory in amnesic patients: Evidence for spared auditory priming. Psychological Science, 5, 20-25.

(Manuscript received August 8, 1995; revision accepted for publication November $20,1996$. 